\title{
CORRELATION BETWEEN PREOPERATIVE VEIN AND ARTERY DIAMETERS AND ARTERIOVENOUS FISTULA OUTCOME IN PATIENTS WITH END-STAGE RENAL DISEASE
}

\author{
ALEXANDRU OPREA ${ }^{1}$, ADRIAN MOLNAR ${ }^{1}$, DAN VLĂDUȚIU ${ }^{2}$, \\ TRAIAN SCRIDON ${ }^{1}$, CĂTĂLIN TRIFAN ${ }^{1}$, DIANA SĂCUI ${ }^{3}$, \\ VASILE SĂSĂRMAN ${ }^{3}$, PETRU ADRIAN MIRCEA ${ }^{4}$
}

'Department of Cardiovascular Surgery, "Niculae Stăncioiu" Heart Institute, Iuliu Haţieganu University of Medicine and Pharmacy, Cluj-Napoca, Romania ${ }^{2}$ Department of Nephrology, Emergency Clinical County Hospital, Iuliu Haţieganu University of Medicine and Pharmacy, Cluj-Napoca, Romania

${ }^{3}$ Department of Cardiovascular Surgery, "Niculae Stăncioiu" Heart Institute, Cluj-Napoca, Romania

${ }^{4}$ Medical Clinic No.1, Department of Gastroenterology, Emergency Clinical County Hospital, Iuliu Haţieganu University of Medicine and Pharmacy, ClujNapoca, Romania

\section{Abstract}

Background and aims. Arteriovenous fistula (AVF) maturation failure rates remain high in patients with end-stage renal disease (ESRD). Although preoperative morphological and functional assessment of blood vessels by duplex ultrasonography (DUS) has been shown to improve AVF maturation, there is no consensus regarding the optimal vein (VD) and artery (AD) diameters to be universally used for AVF creation. To improve patient selection, set out to investigate if there is a correlation between preoperative VD/AD and clinical covariates, and postoperative AVF outcome.

Methods. This was a prospective cohort study conducted during JanuaryAugust 2014. ESRD patients referred to "Niculae Stăncioiu" Heart Institute ClujNapoca, who had a VD $\geq 1.9 \mathrm{~mm}$ and $A D \geq 1.5 \mathrm{~mm}$, as measured by $D U S$, and underwent AVF creation were enrolled. We assessed whether preoperative VD/AD and clinical covariates were associated with AVF maturation rate and primary patency at 2 years after AVF creation.

Results. Of 115 patients referred for AVF creation, 93 were included in the study. Mean ( \pm standard deviation) VD was $3.3 \pm 1.1 \mathrm{~mm}$ and VDs were distributed in quartile $Q 1<2.55 \mathrm{~mm}, Q 2: 2.56-3.10 \mathrm{~mm}, Q 3: 3.11-3.70 \mathrm{~mm}$ and $Q 4:>3.71 \mathrm{~mm}$. Mean $A D$ was $3.3 \pm 1.4 \mathrm{~mm}$ and $A D s$ were distributed in $Q 1<2.55 \mathrm{~mm}, Q 2: 2.56-3.10 \mathrm{~mm}$, Q3: 3.11-3.70 mm, and Q4, $>3.71 \mathrm{~mm}$. AVF maturation rate increased proportionally with VD from Q1 (62\%) to Q2 (70\%), Q3 (82\%) to Q4 (96\%) ( $p=0.03)$. Based on AD, a higher AVF maturation rate was observed in Q3 (86\%), Q4 (83\%) vs Q1 (71\%) and Q2 (67\%). Long-term primary patency of AVFs seemed not to be influenced by VD and $A D$. In older patients and those with peripheral arterial disease, AVF maturation failure tended to be higher.

Conclusions. Our findings suggest that a preoperative $V D \geq 1.9 \mathrm{~mm}$ and $A D$ $\geq 1.5 \mathrm{~mm}$ have a successful maturation rate of AVF greater than $60 \%$ in ESRD patients. The maturation rate of surgical AVF increases proportionally with the size of VD used for AVF creation.

Keywords: end-stage renal disease, arteriovenous fistula, duplex ultrasonography, vein diameter; artery diameter

Manuscript received: 05.06.2018

Received in revised form: 12.07.2018

Accepted: 29.08.2018

Address for correspondence: adimolnar45@yahoo.com 


\section{Introduction}

The incidence of chronic kidney disease (CKD) is increasing worldwide [1]. One of its major implications is the risk of end stage renal disease (ESRD) [2]. In Europe, according to a survey conducted in 16 countries, the incidence of ESRD varies between 81 and 195 per million and the prevalence between 309 and 1670 per million population [3]. The increasing prevalence of ESRD leads to a growing need for renal replacement therapies (RRTs) for survival [1]. Of the RRTs, arteriovenous fistulas (AVFs) are the preferred option for hemodialysis according to The National Kidney Foundation - Kidney Disease Outcomes Quality Initiative (NKF-KDOQI) guidelines and the Fistula First Breakthrough Initiative (FFBI) [4].

However, AVF maturation and failure still represent significant obstacles for successful use of fistula [1]. AVF maturation failure ranges between $20 \%$ and $60 \%$ [5] and was associated with clinical predictors such as patient age, peripheral vascular disease, coronary artery disease, diabetes, non-white race, gender etc. [6].

Preoperative assessment of the morphological and functional parameters of peripheral blood vessels by duplex ultrasonography (DUS) has been shown to improve fistula maturation [7-9]. Because AVFs are created by a direct anastomosis between a native artery and vein, and successful maturation implies an increase in the blood flow rate and diameter of the inflow artery and the draining vein that can support the high blood flow [10], it is important to assess the preoperative vein (VD) and artery (AD) diameters, as well as their morphological characteristics. Even though DUS is routinely used to evaluate veins and arteries suitable for AVF creation, the maturation failure rate remains high [11]. There is no consensus regarding the optimal preoperative $\mathrm{VD}$ and $\mathrm{AD}$ threshold to be universally used for AVF creation, which could predict AVF maturation rate $[12,13]$. The VD threshold reported in different studies between fistula failure and success ranges from 1.6 to $4 \mathrm{~mm}$ $[8,14,15]$. Similarly, the AD threshold reported in literature ranges from 1.5 to $4.1 \mathrm{~mm}$ [16-19].

To improve patient selection for AVF creation, we conducted a prospective cohort study in patients with ESRD in the Department of Cardiovascular Surgery, "Niculae Stăncioiu" Heart Institute, Cluj-Napoca, Romania. Our aim was to evaluate whether preoperative characteristics of the blood vessels were associated with the AVF maturation rate and long-term primary patency. The first epoch study results were previously published and showed that the decrease of digital pressure at 1 and 2 months after AVF creation was not influenced by the arterial remodelling degree, VD or fistula flow in a subset of ESRD patients with preoperative cephalic and basilic VDs $>1.7 \mathrm{~mm}$ and brachial AD $>2 \mathrm{~mm}$ [20]. We also showed that vein morphology was correlated with AVF outcome [21].

End-of-study results are reported here. We assessed if there was a correlation between preoperative $\mathrm{VD}$ and $\mathrm{AD}$, as measured by DUS, and the postoperative AVF maturation rate and long-term primary patency, and tried to identify a threshold to be used during pre-operative evaluation. We also assessed if patient clinical status correlated with postoperative AVF outcome.

\section{Material and methods Study design and participants}

This was a prospective cohort study conducted in the Department of Cardiovascular Surgery, "Niculae Stăncioiu" Heart Institute, Cluj-Napoca, Romania, during January 2014 - August 2014. The study was approved by the ethical committee of the hospital and of the "Iuliu Haţieganu" University of Medicine and Pharmacy, ClujNapoca, Romania, and was conducted in accordance with the principles of the Declaration of Helsinki. Informed consent was obtained from all patients before inclusion in the study.

Patients with ESRD referred to our department were considered eligible for study inclusion if they had: vessels suitable for AVF creation as established by clinical examination and ultrasonography, with a $\mathrm{VD} \geq 1.9 \mathrm{~mm}$, and $\mathrm{AD} \geq 1.5 \mathrm{~mm}$, and if written informed consent was given prior to enrolment. Regardless of whether they had or not a previous arteriovenous access, patients were included in the study. Any of the following were considered reason for exclusion: previous diagnosis of stenosis or thrombosis in the draining veins to be used for AVF creation, concomitant diagnosis of other disease and/or ongoing treatment that may influence AVF maturation, and physician decision that patients may not comply with study procedures. Prior to AVF creation, patients were clinically examined and baseline patient demographic data, clinical comorbidities, and dialysis status were recorded. DUS of artery and veins was performed by the same vascular surgeon and the arteriovenous access type was decided based on the KDOQI and Society for Vascular Surgery guidelines [22]. Patient-specific procedure was determined by the operating surgeon based on each patient's history, clinical status and preoperative DUS evaluation of the vessels to be used for AVF creation. The surgical interventions consisted in radiocephalic, brachiocephalic or brachiobasilic fistula, and were performed using standard techniques. We evaluated if a correlation between preoperative diameter of the inflow artery and of the cephalic vein on the postoperative AVF maturation rate and primary patency at 2 years after AVF creation could be observed.

DUS evaluation of the blood vessels used for AVF creation

Patients were examined in sitting position, after a tourniquet was applied on the upper third of the forearm or arm, while the arm was resting on an adjustable supporting stand. Before DUS examination, the radial artery was palpated at wrist level, the brachial artery at the anterior side of the elbow and veins along the trajectory, to identify their direction and exact position. The ultrasound examination was performed using the NextGen LOGIQTM doppler ultrasound 
machine. A 2-D broad-spectrum linear probe of 7.0 to 15.0 $\mathrm{MHz}$ was used. The size of the arteries was assessed in real time, grey scale, and on longitudinal sections at the level of wrist for the radial artery, and antecubital fossa for the brachial artery. The ADs selected for AVF location were recorded. Vein evaluation was performed through the forearm and upper-arm. VDs were measured in cross-section. When the vein image was frozen on the screen, the cross-sectional area was calculated by an automatic function. The risk of underestimating the vein size due to compression exercised by the transducer was minimized by using big amounts of gel. Assuming that the narrowest portion of the vein is a good indicator of pre-existing stenosis, decreased AVF flow or risk for AVF failure, the minimum VD in the location selected for AVF creation was recorded. DUS was performed by the same vascular surgeon to ensure consistency of measurements. Depending on the vessels size, radiocephalic AVF type was preferred first, followed by brachiocephalic and brachiobasilic AVF types, as also proposed by KDOQI and Society for Vascular Surgery guidelines [22].

\section{Surgical procedure for AVF creation}

Based on preoperative findings, radial-cephalic, brachial-cephalic or transposed brachial-basilic AVFs were created by the same vascular surgeon.

\section{Postoperative AVF assessment}

AVF was considered mature if permitted cannulation with 2 needles for $2 / 3$ dialysis runs within 1 month and up to 6 months after its creation, at an average blood flow rate of 300 to $450 \mathrm{ml} /$ minute for 3.5 to 4.0 hours [23]. In this analysis, AVF maturation and patency were assessed at 2 years after AVF creation.

\section{Statistical analysis}

Statistical analyses were performed with Epi InfoTM 7 software (CDC, USA). For descriptive statistics, continuous data were tabulated as prevalence and percentages, and categorical variables as mean values with standard deviation $( \pm \mathrm{SD}$ ) or $95 \%$ confidence intervals (CIs). To find the optimal minimum VD and AD to be used for preoperative evaluation, the frequency distribution of $\mathrm{VD}$ and $\mathrm{AD}$ in the entire study population was assessed. The 25th, 50th and 75th percentile rank values were used to define $\mathrm{VD}$ and $\mathrm{AD}$ quartiles. $\mathrm{VD}$ and $\mathrm{AD}$ recorded in each patient were included either within the 1st, 2nd, 3rd, or 4th quartile (Q1, Q2, Q3, or Q4).

To compare the continuous variables, ANOVA Parametric Test for Inequality of Population Means was used. To assess the association between categorical variables, chi-square test was used; to determine if there was an association between $\geq 2$ categorical variables, the values were automatically compared between one another in all possible combinations and a mid $p$ value was generated. P-value was considered statistically significant if less than 0.05 . Correlation between two variables was assessed by Pierson correlation test: if $\mathrm{r}=1$, a strong (positive/negative) correlation was considered; if $r=-1+0.5$ was considered a medium (positive/negative correlation); and if $r=1+0.25$ was considered a weak (positive/negative) correlation.

\section{Results}

\section{Demographic characteristics and AVF type}

Of 115 patients referred to our department for AVF creation during the study period, 93 were eligible for study inclusion. Of the 22 patients excluded, 19 refused to be included in the study, 2 died and 1 underwent kidney transplant. Baseline demographic characteristics of study participants are showed in Table I. The number of male patients was around two times higher than the numbers of females.

Table I. Demographic characteristics and clinical data at baseline.

\begin{tabular}{|l|l|l|}
\hline \multirow{2}{*}{ Category } & \multicolumn{2}{|l|}{ Overall population $(\mathbf{N}=93)$} \\
\cline { 2 - 3 } & $\mathrm{n}$ & mean \pm SD or \% (95\% CI) \\
\hline Age (years) & 93 & $60.5 \pm 11.8$ \\
\hline Female & 35 & $37.6(27.8-48.3)$ \\
\hline Male & 58 & $62.4(51.7-72.2)$ \\
\hline Urban area & 55 & $59.1(48.5-69.2)$ \\
\hline Rural area & 38 & $40.9(30.8-51.5)$ \\
\hline Smoker & 20 & $21.5(13.7-31.2)$ \\
\hline DM & 32 & $34.4(24.9-45.0)$ \\
\hline AHT & 81 & $87.1(78.6-93.2)$ \\
\hline IC & 31 & $33.3(56.1-76.1)$ \\
\hline PAD & 18 & $19.4(11.9-28.9)$ \\
\hline Before dialysis start & 34 & $36.6(26.8-47.2)$ \\
\hline
\end{tabular}

$\mathrm{N}$, total number of patients included in the analysis; $\mathrm{n}$, number of patients in a given category; SD, standard deviation; CI, confidence interval; DM, diabetes mellitus; AHT, arterial hypertension; IC, ischemic cardiomyopathy; $\mathrm{PAD}$, peripheral arterial disease.

\section{Overall AVF maturation rate and long-term functional patency}

The distribution of AVF types was as follows: 47 patients $(50.5 \%$; 95\% CI: 40.0-61.1) had radiocephalic AVF placed, 37 patients (39.8\%; 95\% CI: 29.8-50.5) had brachiocephalic AVF, and 9 patients (9.7\%; 95\% CI: 4.517.6) had brachiobasilic AVF. Of the 93 access procedures, 71 AVFs (76.3\%; 95\% CI: 66.40-84.54) matured and were further used. No difference in AVF maturation rate was recorded in patients with radiocephalic (32 of 47 [68.1\%]), brachiocephalic (31 of 37 [83.8\%]) and brachiobasilic (8 of 9 [88.9\%]) AVFs (Table II). The total number of AVFs that failed to mature was $22(22.3 \%$; 95\% CI: $15.5-33.6)$ and were not further used or followed-up.

Of the 71 mature AVFs, 45 (81.8\%; 95\% CI: 69.190.9) achieved functional patency at 2 years after AVF creation and $10(18.18 \%$; 9.1-30.9) were non-functional. 16 AVFs that matured were lost to follow-up at 2 years after AVF creation, 9 patients died, 5 patients underwent renal transplant, and 2 patients did not start dialysis.

The highest number of functional AVF at 2 years after AVF creation was recorded in patients with radiocephalic AVF (23 of 26 [88.5\%]) and brachiocephalic AVF (20 of 
$23[87.0 \%]$ ) (Table III). The percentage of non-functional AVFs was increased in patients with brachiobasilic AVF (4 of $6[66.7 \%])$, the difference being statistically significant compared to the percentage of non-functional radiocephalic (3 of $26[11.5 \%])$ and brachiocephalic (3 of $23[13.0 \%])$ AVFs $(\mathrm{p}=0.002)$.

Table II. Overall maturation rate based on baseline characteristics and DUS evaluation.

\begin{tabular}{|c|c|c|c|c|c|c|}
\hline \multirow{2}{*}{\multicolumn{2}{|c|}{ Category }} & \multicolumn{2}{|c|}{ Mature AVF (N=71) } & \multicolumn{2}{|c|}{ Non-mature AVF $(\mathrm{N}=22)$} & \multirow[t]{2}{*}{ p-value } \\
\hline & & $\mathrm{n}$ & mean $\pm \mathrm{SD}$ or $\%(95 \% \mathrm{CI})$ & $\mathrm{n}$ & mean $\pm \mathrm{SD}$ or $\%(95 \% \mathrm{CI})$ & \\
\hline \multicolumn{2}{|l|}{ Age (years) } & 71 & $59 \pm 11.1$ & 22 & $65 \pm 13.1$ & 0.054 \\
\hline \multirow[t]{2}{*}{ Gender } & Female & 26 & $74.3(56.7-87.5)$ & 9 & $25.7(12.5-43.3)$ & \multirow[t]{2}{*}{0.35} \\
\hline & Male & 45 & $77.6(64.7-87.5)$ & 13 & $22.4(12.5-35.3)$ & \\
\hline \multirow[t]{2}{*}{ Area } & Urban & 42 & $76.4(63.00-86.8)$ & 13 & $23.64(13.2-37.0)$ & \multirow[t]{2}{*}{0.49} \\
\hline & Rural & 29 & $76.3(59.8-88.6)$ & 9 & $23.7(11.4-40.2)$ & \\
\hline \multirow[t]{2}{*}{ Smoker } & Yes & 15 & $75.0(50.9-91.3)$ & 5 & $25(8.7-49.1)$ & \multirow[t]{2}{*}{0.43} \\
\hline & No & 56 & $76.5(65.4-85.8)$ & 17 & $23.3(14.2-34.7)$ & \\
\hline \multirow[t]{2}{*}{ DM } & Yes & 25 & $78.1(60.0-90.7)$ & 7 & $21.9(9.3-40.0)$ & \multirow[t]{2}{*}{0.39} \\
\hline & No & 46 & $75.4(62.7-85.5)$ & 15 & $24.6(14.5-37.3)$ & \\
\hline \multirow[t]{2}{*}{ AHT } & Yes & 61 & $75.3(64.5-84.2)$ & 20 & $24.6(15.8-35.5)$ & \multirow[t]{2}{*}{0.29} \\
\hline & No & 10 & $83.3(51.6-97.9)$ & 2 & $16.7(2.1-48.4)$ & \\
\hline \multirow[t]{2}{*}{ IC } & Yes & 24 & $72.4(58.9-90.4)$ & 7 & $22.6(9.6-41.1)$ & \multirow[t]{2}{*}{0.43} \\
\hline & No & 47 & $75.8(63.3-85.8)$ & 15 & $24.2(14.2-36.7)$ & \\
\hline \multirow[t]{2}{*}{ PAD } & Yes & 11 & $61.1(35.8-82.7)$ & 7 & $38.9(17.3-64.3)$ & \multirow[t]{2}{*}{0.056} \\
\hline & No & 60 & $80.0(69.2-88.4)$ & 15 & $20(11.7-30.8)$ & \\
\hline \multirow[t]{2}{*}{ Before dialysis } & Yes & 27 & $79.4(62.1-91.3)$ & 7 & $20.6(8.7-37.9)$ & \multirow[t]{2}{*}{0.31} \\
\hline & No & 44 & $74.6(61.6-85.0)$ & 15 & $25.4(15.0-38.4)$ & \\
\hline \multirow[t]{3}{*}{ AVF type } & Radiocephalic & 32 & $68.1(52.9-80.9)$ & 15 & $31.9(9.1-47.1)$ & \multirow[t]{3}{*}{0.15} \\
\hline & Brachiocephalic & 31 & $83.8(68.0-93.8)$ & 6 & $16.2(6.2-32.0)$ & \\
\hline & Brachiobasilic & 8 & $88.9(51.8-99.7)$ & 1 & $11.1(0.3-48.3)$ & \\
\hline
\end{tabular}

Note: statistical analysis performed by ANOVA chi-square test and ANOVA Parametric Test for Inequality of Population Means (p-value was considered statistically significant if $\leq 0.05$ ). DUS, duplex ultrasonography; $\mathrm{N}$, total number of patients; $\mathrm{n}$, number of patients in a given category; SD, standard deviation; CI, confidence interval; DM, diabetes mellitus; AHT, arterial hypertension; IC, ischemic cardiomyopathy; PAD, peripheral arterial disease; AVF; arteriovenous fistula.

Table III. Functional patency at 2 years after AVF creation based on baseline characteristics and DUS evaluation.

\begin{tabular}{|c|c|c|c|c|c|c|}
\hline \multicolumn{2}{|l|}{ Category } & \multicolumn{2}{|c|}{ Functional AVF (N=45) } & \multicolumn{2}{|c|}{ Non-functional AVF $(\mathrm{N}=10)$} & \multirow[t]{2}{*}{ p-value } \\
\hline & & $\mathrm{n}$ & mean $\pm \mathrm{SD}$ or $\%(95 \% \mathrm{CI})$ & $\mathrm{n}$ & mean $\pm \mathrm{SD}$ or $\%(95 \% \mathrm{CI})$ & \\
\hline \multicolumn{2}{|l|}{ Age (years) } & 45 & $59 \pm 11.8$ & 10 & $65 \pm 11.3$ & 0.19 \\
\hline \multirow[t]{2}{*}{ Gender } & Female & 15 & $75.0(50.9-91.3)$ & 5 & $25.0(8.7-49.1)$ & \multirow[t]{2}{*}{0.17} \\
\hline & Male & 30 & $85.7(69.7-95.2)$ & 5 & $14.3(4.8-30.3)$ & \\
\hline \multirow[t]{2}{*}{ Area } & Urban & 24 & $80.0(61.4-92.3)$ & 6 & $20.0(7.7-38.6)$ & \multirow[t]{2}{*}{0.36} \\
\hline & Rural & 21 & 84.0 (63.9-95.5) & 4 & $16.0(4.5-36.1)$ & \\
\hline \multirow[t]{2}{*}{ Smoker } & Yes & 7 & $77.8(40.0-97.2)$ & 2 & $22.2(2.8-60.0)$ & \multirow[t]{2}{*}{0.36} \\
\hline & No & 38 & $82.6(68.6-92.2)$ & 8 & $17.4(7.8-31.4)$ & \\
\hline \multirow[t]{2}{*}{$\mathbf{D M}$} & Yes & 15 & $93.8(69.8-99.8)$ & 1 & $6.3(0.2-30.2)$ & \multirow[t]{2}{*}{0.07} \\
\hline & No & 30 & $76.9(60.7-88.9)$ & 9 & $23.1(11.1-39.3)$ & \\
\hline \multirow[t]{2}{*}{ AHT } & Yes & 38 & $82.6(68.6-92.2)$ & 8 & $17.4(7.8-31.4)$ & \multirow[t]{2}{*}{0.36} \\
\hline & No & 7 & $77.8(40.0-97.2)$ & 2 & $22.2(2.8-60.0)$ & \\
\hline \multirow[t]{2}{*}{ IC } & Yes & 16 & $80.0(56.3-94.3)$ & 4 & $20.0(5.7-43.7)$ & \multirow[t]{2}{*}{0.39} \\
\hline & No & 29 & 83.0 (66.4-93.4) & 6 & $17.1(6.6-33.6)$ & \\
\hline \multirow[t]{2}{*}{ PAD } & Yes & 5 & $71.4(29.0-96.3)$ & 2 & $28.6(3.7-71.0)$ & \multirow[t]{2}{*}{0.23} \\
\hline & No & 40 & $83.3(69.8-92.5)$ & 8 & $16.7(7.5-30.2)$ & \\
\hline \multirow[t]{2}{*}{ Before dialysis } & Yes & 17 & $89.5(66.9-98.7)$ & 2 & $10.5(1.3-33.1)$ & \multirow[t]{2}{*}{0.16} \\
\hline & No & 28 & $77.3(60.9-89.9)$ & 8 & 22.2 (10.1-39.2) & \\
\hline \multirow[t]{3}{*}{ AVF type } & Radiocephalic & 23 & $88.5(69.9-97.6)$ & 3 & $11.5(2.5-30.2)$ & \multirow[t]{3}{*}{0.002} \\
\hline & Brachiocephalic & 20 & $87.0(66.4-97.2)$ & 3 & $13.0(2.8-33.6)$ & \\
\hline & Brachiobasilic & 2 & $33.3(4.3-77.7)$ & 4 & 66.7 (22.3-95.7) & \\
\hline
\end{tabular}

Note: statistical analysis performed by ANOVA chi-square test and ANOVA Parametric Test for Inequality of Population Means (p-value was considered statistically significant if $\leq 0.05$ ). DUS, duplex ultrasonography; $\mathrm{N}$, total number of patients; $\mathrm{n}$, number of patients in a given category; SD, standard deviation; CI, confidence interval; BMI, body mass index; DM, diabetes mellitus; AHT, arterial hypertension; IC, ischemic cardiomyopathy; PAD, peripheral arterial disease; AVF; arteriovenous fistula. 
Impact of preoperative $V D$ and $A D$ on the $A V F$ maturation and long-term functional patency

The mean VD of the overall population included in this analysis was $3.3 \pm 1.1 \mathrm{~mm}$. To find the optimal minimum diameters to be used for preoperative evaluation, VD were distributed in the following quartiles: Q1, $<2.55$ $\mathrm{mm}$; Q2, 2.56 to $3.10 \mathrm{~mm}$; Q3, 3.11 to $3.70 \mathrm{~mm}$; Q4, $>3.71 \mathrm{~mm}$. The mean AD was $3.3 \pm 1.4$. VD quartiles were defined as follows: Q1, $<2.55 \mathrm{~mm}$; Q2, 2.56 to $3.10 \mathrm{~mm}$; Q3, 3.11 to $3.70 \mathrm{~mm}$; Q4, $>3.71 \mathrm{~mm}$. The percentage of patients with $\mathrm{VD}$ and $\mathrm{AD}$ included within a quartile was similar between quartiles (Figure 1A and 1B, respectively).

AVF maturation rate increased proportionally with VD, the prevalence was statistically significant, being increased from Q1 to Q4 ( $\mathrm{p}=0.03$ ) (Table IV). Moreover, a positive correlation between VD increase and maturation rate increase was also observed by Pierson correlation test $(\mathrm{r}=0.3)$.

In Q4, the majority of AVFs were brachiocephalic, while in Q1-Q3 most of AVFs were radiocephalic. The VD means by AVF type $( \pm \mathrm{SD})$ was $4.08 \pm 1.59 \mathrm{~mm}$ for brachiobasilic AVFs, $3.70 \pm 1.30 \mathrm{~mm}$ for brachiocephalic AVFs and $2.83 \pm 0.59$ for radiocephalic AVFs. Even if the difference in diameter means by AVF type was statistically significant $(\mathrm{p}=0.0001)$, maturation rate by AVF type was not statistically significant $(\mathrm{p}=0.15)$ due to the similar maturation rate between brachiobasilic and brachiocephalic AVFs (89\% brachiobasilic, $84 \%$ brachiocephalic and $68 \%$ radiocephalic).

A.

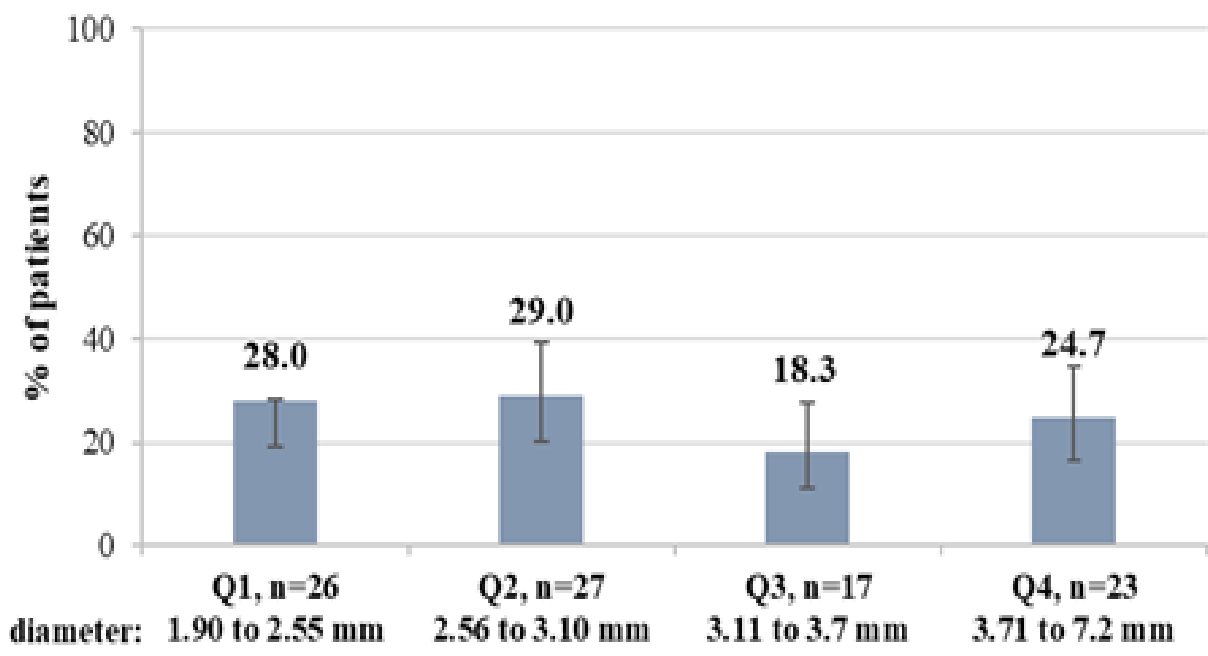

\section{Vein diameter: 1.90 to $2.55 \mathrm{~mm} \quad 2.56$ to $3.10 \mathrm{~mm} \quad 3.11$ to $3.7 \mathrm{~mm} \quad 3.71$ to $7.2 \mathrm{~mm}$}

B.

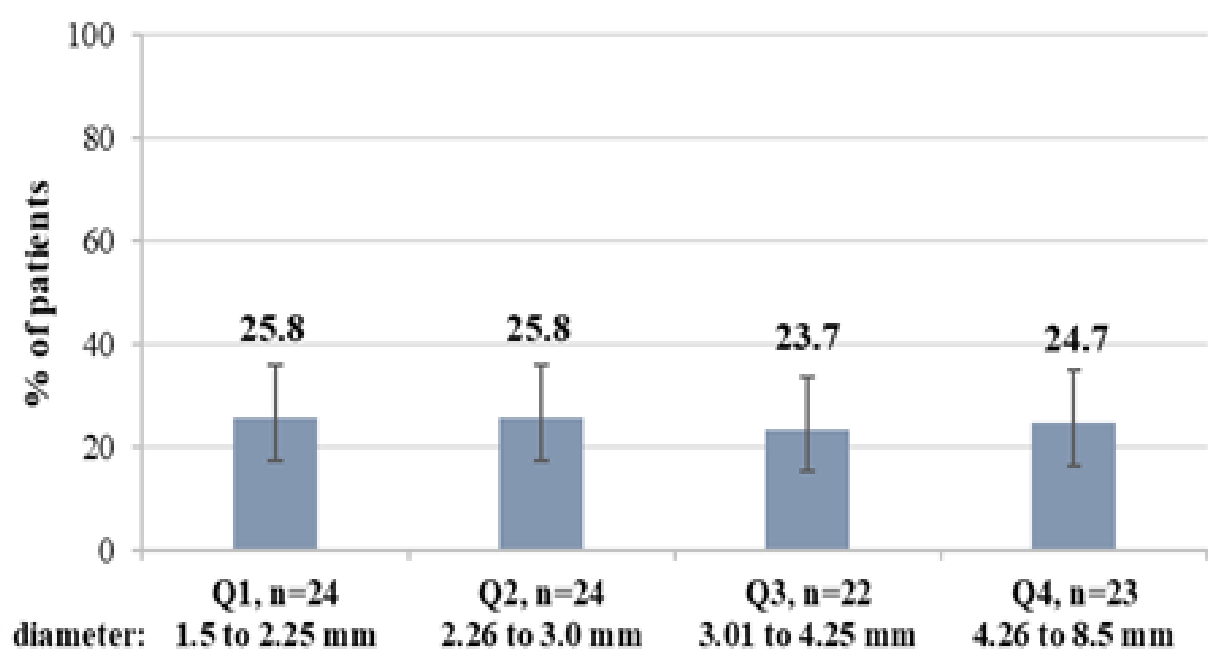

Artery diameter: 1.5 to $2.25 \mathrm{~mm} \quad 2.26$ to $3.0 \mathrm{~mm} \quad 3.01$ to $4.25 \mathrm{~mm} \quad 4.26$ to $8.5 \mathrm{~mm}$

Q, quartile; n, number of patients in a given category.

Figure 1. Distribution of patients in each quartile by preoperative vein diameter (A) and artery diameter (B). 
Table IV. AVF maturation and long-term primary patency by vein and artery diameter quartiles.

\begin{tabular}{|c|c|c|c|c|c|}
\hline Category & Q1 & Q2 & Q3 & Q4 & p-value \\
\hline Vein diameter & $\begin{array}{l}1.90-2.55 \mathrm{~mm} \\
\mathrm{~N}=26\end{array}$ & $\begin{array}{l}2.56-3.10 \mathrm{~mm} \\
\mathrm{~N}=27\end{array}$ & $\begin{array}{l}3.11-3.70 \mathrm{~mm} \\
\mathrm{~N}=17\end{array}$ & $\begin{array}{l}3.71-7.20 \mathrm{~mm} \\
\mathrm{~N}=23\end{array}$ & \\
\hline Fistula maturation, n (\%) & $16(61.5 \%)$ & $19(70.4 \%)$ & $14(82.3)$ & $22(95.7)$ & 0.03 \\
\hline Patency at 2 years, $n(\%)$ & $10(76.9 \%)$ & $13(86.7 \%)$ & $7(77.8)$ & $15(83.3)$ & 0.47 \\
\hline Artery diameter & $\begin{array}{l}1.50-2.25 \mathrm{~mm} \\
\mathrm{~N}=24\end{array}$ & $\begin{array}{l}2.26-3.00 \mathrm{~mm} \\
\mathrm{~N}=24\end{array}$ & $\begin{array}{l}3.01-4.25 \mathrm{~mm} \\
\mathrm{~N}=22\end{array}$ & $\begin{array}{l}4.26-8.50 \mathrm{~mm} \\
\mathrm{~N}=23\end{array}$ & \\
\hline Fistula maturation, n (\%) & $16(66.7)$ & $17(70.8)$ & $19(86.4)$ & $19(82.6)$ & 0.33 \\
\hline Patency at 2 years, $n(\%)$ & $12(92.3)$ & $10(83.3)$ & $12(75.0)$ & $11(78.6)$ & 0.66 \\
\hline
\end{tabular}

Note: statistical analysis performed by ANOVA chi-square test ( $\mathrm{p}$-value was considered statistically significant if $\leq 0.05$ ).

$\mathrm{Q}$, quartile; $\mathrm{N}$, number of patients in a quartile; $\mathrm{n}(\%)$, number (percentage) of patients in a given category.

Long-term patency of AVFs seemed not to be influenced by VD within different quartiles. No statistically significant difference was observed (Table IV).

A higher AVF maturation rate was observed in patients with AD within Q3 (86\%), closely followed by patients with $\mathrm{AD}$ within (Q4), compared to the patients with $\mathrm{AD}$ within Q1 and Q2 (71\% and 67\%, respectively). The difference in maturation rate by quartiles was not statistically significant due to similarities between Q3 and $\mathrm{Q} 4(\mathrm{p}=0.33)$ (Table IV). A very weak positive correlation between AVF maturation rate and VD was also observed by Pierson correlation test $(\mathrm{r}=0.29)$.

In Q4 and Q3, majority of AVFs were brachiocephalic, while in Q2, most of AVFs were radiocephalic, and in Q1, all were radiocephalic. The AD means by AVF type ( \pm SD) was $4.50 \pm 1.21 \mathrm{~mm}$ for brachiocephalic AVFs, 3.82 $\pm 0.76 \mathrm{~mm}$ for brachiobasilic AVFs and $2.31 \pm 0.47$ for radiocephalic AVFs $(\mathrm{p}=0.0)$.

Long-term patency of AVFs seemed not to be influenced by AD distribution within different quartiles $(\mathrm{p}=0.66)$ (Table IV).

Impact of preoperative baseline characteristics and co-morbidities on the AVF maturation and long-term functional patency

AFV maturation failure occurred most likely in older patients (border line statistical significance, $\mathrm{p}=0.054$ ). Patients with peripheral arterial disease (PAD) had lower AVF maturation rate (11 of 18 [61.1\%]) compared to those without diagnosed PAD (maturation rate: 60 of 75 [80\%]), the difference almost reaching a statistical significance $(\mathrm{p}=0.056)$. Gender, living area, tobacco use, diabetes, arterial hypertension (AHT), ischemic cardiomyopathy (IC), AVF creation before or after dialysis start, and AVF type had no effect on the AVF maturation rate (Table II).

Age, gender, living area, tobacco use, BMI, diabetes, AHT, IC, AVF creation before or after dialysis start seemed not to influence long-term patency (Table III).

\section{Discussion}

In our study, we observed no statistically significant difference in maturation rate between radiocephalic, brachiocephalic and brachiobasilic AVFs. Our results are in line with different studies suggesting that the fistula site had no effect on maturation rate $[8,24,25]$, while other studies suggest that forearm fistula are at higher risk of failure $[26,27]$. Of note, in our study, the overall maturation failure rate was $22.3 \%$, which is lower compared to other studies, where a AVF maturation failure up to $60 \%$ was reported [5]. The relatively increased failure rates highlight that the general recommendations provided for AVF placement are not always applicable at individual patient level [22,28].

Regarding the long-term primary patency, our results showed that AVF type seems to influence AVF patency at 2 years after fistula creation. The percentage of patients with non-functional AVF was significantly higher following brachiobasilic AVF placement compared to radiocephalic and brachiocephalic AVFs. However, these findings should be interpreted with caution due to low number of patients with this fistula type included in our study. Since 2004, when FBBI recommended first a target of $40 \%$ AVF utilization among the prevalent haemodialysis and subsequently increased the target to $66 \%$ based on NKF-KDOQI guidelines [29], placement of native AVFs had a significant success in the clinical practice [30]. However, long-term follow-up of AVF patency revealed high rates of failure with up to $51 \%$ by 2 years [31]. Other published data suggest a failure rate varying from $9 \%$ to $53 \%[7,24,25,32,33]$. Compared to these studies, we recorded a relatively low overall failure rate $(18.1 \%)$.

To improve patient selection for AVF creation and to increase AVF maturation rates, NKF-KDOQI guidelines recommended preoperative DUS. Even if DUS is routinely used, and has increased fistula placement and maturation rates [8, 34-36] the maturation failure rate remains high [11]. There is an imperative need to improve patient selection at individual level, but there is no consensus regarding the optimal blood vessel characteristics to be used when taking the decision of AVF placement. Because VD and AD thresholds related with a successful fistula are unclear, in our study we did not attempt to define a minimum VD or $\mathrm{AD}$ when comparing mature versus non-mature AVFs or functional versus non-functional AVFs, but to assess if a threshold related to AVF maturation failure and long-term primary patency loss can be identified in our population. In 
patients with a VD $\geq 1.9 \mathrm{~mm}$, we observed that only AVF maturation rate increased proportionally with $\mathrm{VD}$, from Q1 to Q2 and Q4. Compared to other studies suggesting that a VD ranging between 2 and $3 \mathrm{~mm}$, with basilic $\mathrm{VD} \geq 2.5$ $\mathrm{mm}$ is optimal for AVF creation [11, 13, 25]; while other studies suggest that a cephalic VD $\geq 4 \mathrm{~mm}$ is a predictor for successful AVF maturation [19,30], we suggest that a $\mathrm{VD} \geq 1.9 \mathrm{~mm}$ is optimal for AVF use, regardless of vein type. It is to be noted that the American and European surgeons allow AVF creation with a cephalic VD of 1.5$1.9 \mathrm{~mm}$, and European surgeons also with a basilic VD of 2-2.4 mm [13]. Most studies used mean or maximum VD [30], while we used minimum VD when deciding AVF location. This is the smallest vein size that can be recorded when a patient is vasoconstricted during DUS evaluation. Despite the possible vein vasoconstriction, minimum VD was correlated with fistula maturation rate. Similar findings were reported by Dageforde et al. [11]. In terms of longterm primary patency, no statistically significant difference was observed between patients from Q1, Q2, Q3 and Q4. Our observations are comparable with previous studies demonstrating that VD as measured by DUS is associated with fistula outcomes [30,37]. Vein size seems to be an important predictor of fistula maturation, but it should also be associated with arterial factors and blood flow [30]. Some studies have demonstrated a correlation between large vein sizes and improved AVF maturation and patency [11,38], but the association between artery size and maturation rate is controversial [19]. In our study, we observed a higher AVF maturation rate in Q3 and Q4 compared to Q1 and Q2. The lowest AD included in our analysis was $1.5 \mathrm{~mm}$. Different studies suggest that a preoperative $\mathrm{AD}<1.5 \mathrm{~mm}$ or $<1.6 \mathrm{~mm}$ is associated with AVF early failure [16,17,39], while in other studies, when using a minimum AD of 2 $\mathrm{mm}$, no association between AD and AVF outcome was found $[19,40,41]$. No statistically significant difference was observed between patients with AD within Q1, Q2, Q3 and $\mathrm{Q} 4$, and long-term primary patency outcome. In some studies, the AD considered optimal for AVF creation was $\geq$ $1.5 \mathrm{~mm}[16,25]$ or $\geq 2 \mathrm{~mm}$ [42], while other studies suggest poor AVF functionality when radial AD is smaller than 1.5$2.3 \mathrm{~mm}$ [16-18]. The use of preoperative vessel mapping, in addition to diameter assessment, also excluded the small and diseased veins and arteries, which may lead to AVF failure.

Furthermore, we also assessed if patients baseline characteristics and co-morbidities were related with AVF outcome. We showed that older age increased the AVF maturation failure Similar results have been reported in literature $[7,42-44]$. This may be explained by the high prevalence of co-morbidities, poor quality of life and short life expectancy in elderly patients, which is associated with AVF maturation failure and decreased primary and cumulative AVF patency [45]. Regarding patient gender, we found no statistically significant difference between female and male patients. Similar results have been reported by
Lauvao et al. [30]. However, conflicting data regarding the gender influence on the AVF failure are reported. The majority of studies suggest that maturation time is prolonged in women and patency is lower [14,46,47]. We also observed no statistical significant difference in maturation rate and long-term patency in patients with or without diabetes. In contrast with our findings, previous studies have shown that diabetes is directly related with AVF failure and patency loss $[48,49]$. In our study, the number of patients with diabetes was low, which may have led to this contradiction. Regarding smoking history and AHT, our results are in line with previous data [32]. No correlation between AVF maturation failure/longterm primary patency and smoking history and AHT was identified. IC and PAD are also considered predictive risk factors for AVF failure [6]. In our study, only patients with PAD had lower AVF maturation rate. The difference in maturation rate in patients with or without IC was not statistically significant.

We acknowledge that our study has some limitations. One of the limitations is the small size of the included population, which comes from the prospective nature of the study. The defined study duration permitted the inclusion of a limited number of patients. Secondly, we did not assess the calcification status of the inflow artery, which is also a risk factor for poor AVF outcome. Thirdly, due to the nature of follow-up, we were unable to calculate the mean number of days until AVF maturation.

\section{Conclusions}

Our findings suggest that a preoperative $\mathrm{VD} \geq 1.9 \mathrm{~mm}$ and $\mathrm{AD} \geq 1.5 \mathrm{~mm}$, as measured by DUS, have a successful maturation rate over $60 \%$ and that the maturation rate increases with VD increase in patients with ESRD. However, we cannot claim that this can be used as a definitive minimal threshold, but we recommend using DUS to determine the minimal VD and AD. The individual age of the patients and PAD also had a negative influence on the maturation rate. Long-term primary patency loss seems to be higher in patients with brachiobasilic AVFs, however this hypothesis should be further investigated on a larger population size. To take a decision on what type of AVF to be used in ESRD patients, we suggest using a combination between preoperative DUS vessels mapping and clinical examination.

\section{References}

1. Hu H, Patel S, Hanisch JJ, Santana JM, Hashimoto T, Bai H, et al. Future research directions to improve fistula maturation and reduce access failure. Semin Vasc Surg. 2016;29(4):153-171.

2. European Kidney Health Alliance. Recommendations for sustainable kidney care. August 2015. Available from: http://ekha. eu/wp-content/uploads/2016/01/EKHA-Recs-for-SustainableKidney-Care-25.08.2015.pdf .

3. International Society of Nephrology. Kidney Health for Life (KH4L). Chronic kidney disease multinational inventory. International Society of Nephrology: International 
Society of Nephrology. 2014. Available from: https://www. noexperiencenecessarybook.com/7WnWQv/statement-onbehalf-of-the-international-society-of-nephrology-isn-to-the66th-session-of-the-who-regional-committee-for-europe-onhealth-in-the-2030-agenda-for-sustainable-development-and-itsrelation-to-health-2020-agenda-item-5a.html .

4. Vascular Access 2006 Work Group. Clinical practice guidelines for vascular access. Am J Kidney Dis. 2006;48 Suppl 1:S176-S247. 5. Kosa SD, Al-Jaishi AA, Moist L, Lok CE. Preoperative vascular access evaluation for haemodialysis patients. Cochrane Database Syst Rev. 2015 Sep 30;(9):CD007013. doi: 10.1002/14651858. CD007013.pub2.

6. Lok CE, Allon M, Moist L, Oliver MJ, Shah H, Zimmerman D. Risk equation determining unsuccessful cannulation events and failure to maturation in arteriovenous fistulas (REDUCE FTM I). J Am Soc Nephrol. 2006;17(11):3204-3212.

7. Malovrh M. Native arteriovenous fistula: preoperative evaluation. Am J Kidney Dis. 2002;39(6):1218-1225.

8. Allon M, Lockhart ME, Lilly RZ, Gallichio MH, Young CJ, Barker J, et al. Effect of preoperative sonographic mapping on vascular access outcomes in hemodialysis patients. Kidney Int. 2001;60(5):2013-2020.

9. Mendes RR, Farber MA, Marston WA, Dinwiddie LC, Keagy BA, Burnham SJ. Prediction of wrist arteriovenous fistula maturation with preoperative vein mapping with ultrasonography. J Vasc Surg. 2002;36(3):460-463.

10. Dixon BS. Why don't fistulas mature? Kidney Int. 2006;70(8):1413-1422.

11. Dageforde LA, Harms KA, Feurer ID, Shaffer D. Increased minimum vein diameter on preoperative mapping with duplex ultrasound is associated with arteriovenous fistula maturation and secondary patency. J Vasc Surg. 2015;61(1):170-176.

12. Pussell BA, Bendorf A, Kerridge IH. Access to the kidney transplant waiting list: a time for reflection. Intern Med J. 2012;42(4):360-363.

13. Nica A, Lok CE, Harris J, Lee TC, Mokrzycki MH, Maya ID, et al. Understanding surgical preference and practice in hemodialysis vascular access creation. Semin Dial. 2013;26(4):520-526.

14. Dunn J, Herscu G, Woo K. Factors influencing maturation time of native arteriovenous fistulas. Ann Vasc Surg. 2015;29(4):704707.

15. Patel ST, Hughes J, Mills JL Sr. Failure of arteriovenous fistula maturation: an unintended consequence of exceeding dialysis outcome quality Initiative guidelines for hemodialysis access. $\mathrm{J}$ Vasc Surg. 2003;38(3):439-445; discussion 445.

16. Parmar J, Aslam M, Standfield N. Pre-operative radial arterial diameter predicts early failure of arteriovenous fistula (AVF) for haemodialysis. Eur J Vasc Endovasc Surg. 2007;33(1):113-115.

17. Jemcov TK. Morphologic and functional vessels characteristics assessed by ultrasonography for prediction of radiocephalic fistula maturation. J Vasc Access. 2013;14(4):356-363.

18. Usta E, Elkrinawi R, Salehi-Gilani S, Adili S, Sonnentag T, Alscher M, et al. Risk factors predicting the successful function and use of autogenous arteriovenous fistulae for hemodialysis. Thorac Cardiovasc Surg. 2013;61(5):438-444.

19. Kakkos SK, Kaplanis N, Papachristou EC, Papadoulas SI, Lampropoulos GC, Tsolakis IA, et al. The Significance of Inflow Artery and Tourniquet Derived Cephalic Vein Diameters on Predicting Successful Use and Patency of Arteriovenous Fistulas for Haemodialysis. Eur J Vasc Endovasc Surg. 2017;53(6):870-878. 20. Oprea A, Molnar A, Scridon T, Mircea PA. Digital pressure in haemodialysis patients with brachial arteriovenous fistula. Indian J Med Sci. 2018:accepted for publication.

21. Oprea A, Molnar A, Encică S, Vlăduţiu DȘ, Scridon GT, Săcui DM, et al. Effect of the veins histopathological characteristics and preexisting medical conditions on arteriovenous fistula maturation and primary patency in patients with end-stage renal disease: an observational, prospective study. Rom J Morphol Embryol. 2017;58(3):871-880.

22. Sidawy AN, Spergel LM, Besarab A, Allon M, Jennings WC, Padberg FT Jr, et al. The Society for Vascular Surgery: clinical practice guidelines for the surgical placement and maintenance of arteriovenous hemodialysis access. J Vasc Surg. 2008;48(5 Suppl):2S-25S.

23. Lee T, Mokrzycki M, Moist L, Maya I, Vazquez M, Lok CE, et al. Standardized definitions for hemodialysis vascular access. Semin Dial. 2011;24(5):515-524.

24. Tordoir JH, Rooyens P, Dammers R, van der Sande FM, de Haan M, Yo TI. Prospective evaluation of failure modes in autogenous radiocephalic wrist access for haemodialysis. Nephrol Dial Transplant. 2003;18(2):378-383.

25. Elsharawy MA. Prospective evaluation of factors associated with early failure of arteriovenous fistulae in hemodialysis patients. Vascular. 2006;14(2):70-74.

26. Peterson WJ, Barker J, Allon M. Disparities in fistula maturation persist despite preoperative vascular mapping. Clin J Am Soc Nephrol. 2008;3(2):437-441.

27. Ernandez T, Saudan P, Berney T, Merminod T, Bednarkiewicz M, Martin PY. Risk factors for early failure of native arteriovenous fistulas. Nephron Clin Pract. 2005;101(1):c39-c44.

28. III. NKF-K/DOQI Clinical Practice Guidelines for Vascular Access: update 2000. Am J Kidney Dis. 2001;37(1 Suppl 1):S137-S181.

29. Neumann ME. "Fistula first" initiative pushes for new standards in access care. Nephrol News Issues. 2004;18(9):43, 47-48.

30. Lauvao LS, Ihnat DM, Goshima KR, Chavez L, Gruessner AC, Mills JL Sr. Vein diameter is the major predictor of fistula maturation. J Vasc Surg. 2009;49(6):1499-1504.

31. Al-Jaishi AA, Oliver MJ, Thomas SM, Lok CE, Zhang JC, Garg AX, et al. Patency rates of the arteriovenous fistula for hemodialysis: a systematic review and meta-analysis. Am J Kidney Dis. 2014;63(3):464-478.

32. Schild AF, Prieto J, Glenn M, Livingstone J, Alfieri K, Raines J. Maturation and failure rates in a large series of arteriovenous dialysis access fistulas. Vasc Endovascular Surg. 2004;38(5):449453.

33. Feldman HI, Joffe M, Rosas SE, Burns JE, Knauss J, Brayman $\mathrm{K}$. Predictors of successful arteriovenous fistula maturation. Am J Kidney Dis. 2003;42(5):1000-1012.

34. Ascher E, Gade P, Hingorani A, Mazzariol F, Gunduz Y, Fodera $\mathrm{M}$, et al. Changes in the practice of angioaccess surgery: impact of dialysis outcome and quality initiative recommendations. J Vasc Surg. 2000;31(1 Pt 1):84-92.

35. Gibson KD, Caps MT, Kohler TR, Hatsukami TS, Gillen DL, Aldassy M, et al. Assessment of a policy to reduce placement of prosthetic hemodialysis access. Kidney Int. 2001;59(6):23352345.

36. Wong CS, McNicholas N, Healy D, Clarke-Moloney M, Coffey JC, Grace PA, et al. A systematic review of preoperative duplex ultrasonography and arteriovenous fistula formation. J Vasc Surg. 2013;57(4):1129-1133. 
37. Khavanin Zadeh M, Gholipour F, Naderpour Z, Porfakharan M. Relationship between Vessel Diameter and Time to Maturation of Arteriovenous Fistula for Hemodialysis Access. Int J Nephrol. 2012;2012:942950. doi: 10.1155/2012/942950.

38. Farber A, Imrey PB, Huber TS, Kaufman JM, Kraiss LW, Larive B, et al. Multiple preoperative and intraoperative factors predict early fistula thrombosis in the Hemodialysis Fistula Maturation Study. J Vasc Surg. 2016;63(1):163-170.e6.

39. Wong V, Ward R, Taylor J, Selvakumar S, How TV, Bakran A. Reprinted article "Factors associated with early failure of arteriovenous fistulae for haemodialysis access". Eur J Vasc Endovasc Surg. 2011;42 Suppl 1:S48-S54.

40. Korten E, Toonder IM, Schrama YC, Hop WC, van der Ham $\mathrm{AC}$, Wittens $\mathrm{CH}$. Dialysis fistulae patency and preoperative diameter ultrasound measurements. Eur J Vasc Endovasc Surg. 2007;33(4):467-471.

41. Ives CL, Akoh JA, George J, Vaughan-Huxley E, Lawson H. Pre-operative vessel mapping and early post-operative surveillance duplex scanning of arteriovenous fistulae. J Vasc Access. 2009;10(1):37-42.

42. Woo K, Ulloa J, Allon M, Carsten CG 3rd, Chemla ES, Henry $\mathrm{ML}$, et al. Establishing patient-specific criteria for selecting the optimal upper extremity vascular access procedure. J Vasc Surg. 2017;65(4):1089-1103.e1.
43. Rao RK, Azin GD, Hood DB, Rowe VL, Kohl RD, Katz SG, et al. Basilic vein transposition fistula: a good option for maintaining hemodialysis access site options? J Vasc Surg. 2004;39(5):10431047.

44. Allon M. Arteriovenous Grafts: Much Maligned But in Need of Reconsideration? Semin Dial. 2017;30(2):125-133.

45. Tordoir JHM, Bode AS, van Loon MM. Preferred strategy for hemodialysis access creation in elderly patients. Eur J Vasc Endovasc Surg. 2015;49(6):738-743.

46. Almasri J, Alsawas M, Mainou M, Mustafa RA, Wang Z, Woo K, et al. Outcomes of vascular access for hemodialysis: A systematic review and meta-analysis. J Vasc Surg. 2016;64(1):236243.

47. Miller CD, Robbin ML, Allon M. Gender differences in outcomes of arteriovenous fistulas in hemodialysis patients. Kidney Int. 2003;63(1):346-352.

48. Huijbregts HJ, Bots ML, Moll FL, Blankestijn PJ; CIMINO members. Hospital specific aspects predominantly determine primary failure of hemodialysis arteriovenous fistulas. J Vasc Surg. 2007;45(5):962-967.

49. Monroy-Cuadros M, Yilmaz S, Salazar-Bañuelos A, Doig C. Risk factors associated with patency loss of hemodialysis vascular access within 6 months. Clin J Am Soc Nephrol. 2010;5(10):17871792. 